\begin{tabular}{lc} 
Sharif University of Technology & Scientia Iranica \\
SCIENTIA & Transactions F: Nanotechnology \\
I RAN ICA & http://scientiairanica.sharif.edu \\
\hline
\end{tabular}

\title{
Analytical view of magnetic hydrodynamic rotating flow of Barium Ferrite nanofluid with viscous dissipation
}

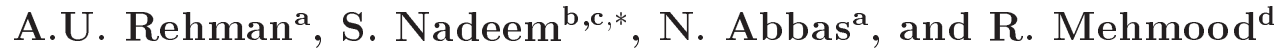 \\ a. Department of Mathematics, Quaid-I-Azam University 45320, Islamabad 44000, Pakistan. \\ b. Mathematics and Its Applications in Life Sciences Research Group, Ton Duc Thang University, Ho Chi Minh City 700000 , \\ Vietnam. \\ c. Faculty of Mathematics and Statistics, Ton Duc Thang University, Ho Chi Minh City 700000, Vietnam. \\ d. Department of Mathematics, Faculty of Natural Science, HITEC University 47080, Taxila Cannt 47070, Pakistan.
}

Received 18 September 2019; received in revised form 30 June 2020; accepted 14 September 2020

\section{KEYWORDS}

Stretching surface;

Ferro fluid;

MHD;

Viscous dissipation.

\begin{abstract}
This study involves an MHD rotating nanofluid flow over a stretching surface. Base fluid, via water, and kerosene liquids are employed with Barium Ferrite $\mathrm{BaO} .6 \mathrm{Fe}_{2} \mathrm{O}_{3}$ nanosize particles in our investigation, which are known as ferrofluid. Governing equations involving partial derivatives of the problem are established and converted into dimensionless forms of ordinary derivatives by means of suitable and compatible similarity transformations. The transformed system of equations is tackled by a reliable numerical scheme as a midpoint integration pattern together with an extrapolation scheme of Richardson. This numerical pattern is launched in maple software. Variations in flow, velocity and temperature due to the involved parameters are recorded via graphs and tables. The authors' targeted quantities, like local tangential stress and heat transfer rate at the wall, are calculated for nanofluid. Heat transfer rate at surface level $z=0$ rises with a rise in solid nanoparticle $\varphi$, but it falls with a rise in magnetic factor $M$, spin factor $\lambda$, and Eckert number Ec. The higher heat transfer rate is recorded in the case of kerosene grounded Ferro fluid. Base fluid plays a vital role in determinations. Water is preferred as the base fluid for significant outcomes.
\end{abstract}

(C) 2020 Sharif University of Technology. All rights reserved.

\section{Introduction}

Nanofluids, because of their rapid heat transmitting capability, have attained much importance over the last decade or so. Due to their higher thermal conductivity, they are proven to have more effective heat transmission than customary heat transporting liquids such as water, engine oil, etc. The paradox "how can heat transfer characteristics be enhanced swiftly?" was

*. Corresponding author. Tel.: +923005117317

E-mail address: sohail.nadeem@tdtu.edu.vn (S. Nadeem)

doi: $10.24200 /$ SCI.2020.54304.3692 probably first explored by Choi and Eastman [1] by introducing the concept of nanofluid. This remarkable idea brought about a revolution in several technological industries involving the heat transfer phenomenon. Later, Lee and Choi [2] applied nano-material suspension in an advanced cooling system. Pak and Cho [3] analyzed heat transfer and hydrodynamics using oxide nanoparticles with base fluid. Wang et al [4] worked on a nano-material mixture with base fluid for thermal conductivity. Experimental work on nanomaterial with base fluid has been undertaken by $\mathrm{Li}$ and Xuan [5]. Buongiorno [6] discussed the convective transport of spread fluid with metal oxide nano subdivisions. Kakaç and Pramuanjaroenkij [7] worked on enhancement of 
the convective heat transfer of the nanomaterial with base fluid. They provided a comprehensive review on the convective heat transfer of the nanomaterial fluid flow. A two phase flow of nanomaterial with base fluid to analyze the mass transfer enhancement was studied by Xuan [8]. Current and future applications of nanofluid in different fields of engineering and industry has been discussed by Wong and Leon [9]. Avramenko et al. [10] studied the heat transfer of nanofluid over film condensation of moving vapor. Avramenko et al. $[11,12]$ also studied the heat transfer of nanomaterial with base fluid at vertical and flat surfaces. Numerical investigations of the nanomaterial flow of unsteady with variable viscosity at a permeable shrinking surface were analyzed by Ahmed et al. [13]. Numerous works have been undertaken for nanofluid at the stretching surface due to the demands of their applications (see [14-19]).

Flow over stretched surfaces has numerous uses in industrial procedures mainly in drawing filaments and thin panes. Almost every industry regarding thin layers of glass and plastic is related to enlarging the surface. In these industries, the worth of end products is dependent on the rate of transmission of heat at enlarging the surface, and because of this many scholars have dedicated themselves to this issue. The initiations and investigations of flow depending only on the stretching surface have been clarified by Crane [20]. Due to the stretching surface, the three dimensional fluid flow at a flat sheet has been analyzed by Wang [21]. Viscoelastic fluid flow at the stretching sheet was investigated by Rajagopal et al. [22]. The uniqueness flow of Navier Stokes fluid over a stretching surface was studied by McLeod and Rajagopal [23]. Non uniform heat source and viscous dissipation with the viscoelastic boundary layer flow at the sheet was studied by Abel et al. [24]. Bataller [25] analyzed the flow over a stretching surface under a non-uniform heat source, thermal radiation and viscous dissipation. Yacob et al. [26], Bachok et al. [27], Sharma et al. [28] and Bachok et al. [29] highlighted the effects on the boundary layer flow under/over moving plates, stretching/shrinking beneath the surface and permeable sheets. They highlighted the effects and heat transfer enhancement. Nazar et al. [30] studied the rotating flow due to a stretching sheet. Sheikholeslami et al. [31] investigated the MHD rotating viscoelastic fluid between the porous and stretching surface. Recently, researchers have greatly investigated boundary layers (see [32-37]) to analyze the effects of the flow of fluid.

Control of heat transmission with the magnetic field is very helpful in various industries, like engineering and gasoline. Hydromagnetic (MHD) flows are widely used in metallurgical processing, refinement of liquid metals from a mixture or an alloy, nuclear reactors, thermal dynamics and ionized-geothermal energy systems etc. Debnath [38] conducted valuable work on the flow of an unsteady MHD boundary layer revolving fluid. Takhar and Nath [39] discussed flow in an unsteady state over an enlarging plane involving MHD revolving fluid. Rosensweig [40] presented the idea of heating magnetic fluid with alternating magnetic power. Kumari and Nath $[41,42]$ examined MHD flow of stagnation over a stretching sheet. Kumaran et al. [43] explored unsteady MHD flow with heat transmission with viscous dissipation over a stretching surface. Khan et al. [44] used the MHD flow of a ferrofluid, due to the stagnation point of heat transfer, at a stretching sheet. Later, Sheikholeslami et al. [45] employed MHD in the finite domain to comprehensively study nanoparticle base fluid flow and heat transmission in a rotating system. The foremost purpose of the current work is to consider the MHD flow of nanoparticlebased fluid over a constantly and linearly stretching surface with viscous effects (see [46-51]). The numerical scheme launched in this study is explained in [52-54]. Wang [55] introduced rotating fluid on a stretching surface. Nadeem et al. [56] explained the boundary layer rotating flow of a two phase nanofluid over a stretching surface.

In the present study, the MHD rotating ferrofluid flow with viscous dissipations over a stretching surface is considered. Two kinds of nanofluid, $\mathrm{BaO} .6 \mathrm{Fe}_{2} \mathrm{O}_{3^{-}}$ water and $\mathrm{BaO} .6 \mathrm{Fe}_{2} \mathrm{O}_{3}$-kerosene, are discussed in this analysis. The developed mathematical model under the assumptions of fluid flow applied the boundary layer approximation on the Navier stoke equations. The mathematical model was developed in the form of partial differential equations. These equations are reduced in the form of ordinary differential equations by means of similarity transformations. The transformed system of equations is tackled by a reliable numerical scheme as a midpoint integration pattern together with an extrapolation scheme of Richardson. This numerical pattern is launched in maple software. The relevant physical parameters are highlighted through graphs and tables.

\section{Formulation of the problem}

Electrically conducting and incompressible nanoparticle-base fluid is considered in space region $z \geq$ 0 . Motion of the fluid is entirely dependent on the motion of elastic boundary $z=0$. Surface $z=0$ is linearly and constantly strained in positive and negative directions of the $x$-axis, such that co-ordinate axes do not displace. Fluid placed on $z=0$ is revolving anti clockwise with a constant angular speed of magnitude $\Omega$ about the positive direction of the $z$ axis normal to the plate. The magnetic field of fixed strength $B_{0}$ is functional along the $z$-axis. The induced magnetic field is neglected. The dominating equations 
controlling the time independent and incompressible flow, together with null pressure gradient, are as follows. The continuity equation is:

$$
\frac{\partial \bar{u}_{1}}{\partial x}+\frac{\partial \bar{u}_{2}}{\partial y}+\frac{\partial \bar{u}_{3}}{\partial z}=0
$$

momentum equations with spin and MHD effects are:

$$
\begin{gathered}
\bar{u}_{1} \frac{\partial \bar{u}_{1}}{\partial x}+\bar{u}_{2} \frac{\partial \bar{u}_{1}}{\partial y}+\bar{u}_{3} \frac{\partial \bar{u}_{1}}{\partial z}-2 \Omega \bar{u}_{2} \\
=v_{n f} \nabla^{2} \bar{u}_{1}-\frac{\sigma_{n f} B_{0}^{2}}{\rho_{n f}} \bar{u}_{1}, \\
\bar{u}_{1} \frac{\partial \bar{u}_{2}}{\partial x}+\bar{u}_{2} \frac{\partial \bar{u}_{2}}{\partial y}+\bar{u}_{3} \frac{\partial \bar{u}_{2}}{\partial z}+2 \Omega \bar{u}_{1} \\
=v_{n f} \nabla^{2} \bar{u}_{2}-\frac{\sigma_{n f} B_{0}^{2}}{\rho_{n f}} \bar{u}_{2}, \\
\bar{u}_{1} \frac{\partial \bar{u}_{3}}{\partial x}+\bar{u}_{2} \frac{\partial \bar{u}_{3}}{\partial y}+\bar{u}_{3} \frac{\partial \bar{u}_{3}}{\partial z}=v_{n f} \nabla^{2} \bar{u}_{3},
\end{gathered}
$$

and the energy equation with viscid effects is:

$$
\begin{aligned}
\bar{u}_{1} \frac{\partial T}{\partial x} & +\bar{u}_{2} \frac{\partial T}{\partial y}+\bar{u}_{3} \frac{\partial T}{\partial z}=\alpha_{n f} \frac{\partial^{2} T}{\partial z^{2}} \\
& +\frac{\mu_{n f}}{\left(\rho C_{p}\right)_{n f}}\left[\left(\frac{\partial \bar{u}_{1}}{\partial z}\right)^{2}+\left(\frac{\partial \bar{u}_{2}}{\partial z}\right)^{2}\right],
\end{aligned}
$$

where symbols $\bar{u}_{1}, \overline{u_{2}}$ and $\bar{u}_{3}$ stand for velocity parts in $x, y$ and $z$ directions correspondingly, $\Omega$ stands for magnitude of fixed angular speed of the liquid, $\rho_{n f}$ for the density of nanoparticle-base fluid, $\mu_{n f}$ for the dynamic viscosity of nanoparticle-based fluid, $\alpha_{n f}$ for thermal diffusivity of the nanoparticle-based fluid, $\sigma_{n f}$ for electrical conduction of the nanoparticle-based fluid, $T$ for the temperature of the nanoparticle-based fluid. They are interconnected with substantial nano subdivision percent volume fraction $\varphi$ as:

$$
\begin{aligned}
& \rho_{n f}=\rho_{f}\left[1+\left(\frac{\rho s}{\rho f}\right) \varphi-\varphi\right], \\
& \mu_{n f}=(1-\varphi)^{-2.5} \mu_{f}, \quad \alpha_{n f}=\frac{K_{n f}}{\left(\rho C_{p}\right)_{n f}}, \\
& \left(\rho C_{p}\right)_{n f}=\left(\rho C_{p}\right)_{f}\left[1+\varphi\left(\frac{\left(\rho C_{p}\right)_{s}}{\left(\rho C_{p}\right)_{f}}\right)-\varphi\right], \\
& \frac{K_{n f}}{K_{f}}=\frac{2 K_{f}+K_{s}+2 \varphi\left(K_{s}-K_{f}\right)}{2 K_{f}+K_{s}-2 \varphi\left(K_{s}-K_{f}\right)} .
\end{aligned}
$$

$\left(\rho C_{p}\right)_{s}$ stands for the volume heat capacity of substantial nano subdivisions, $\left(\rho C_{p}\right)_{f}\left(\rho C_{p}\right)_{n f}$ stand for volume heat capacities of the base liquid and the nanoparticle-based liquid, respectively, and $\varphi$ for sub- stantial nano subdivisions' percent volume fraction. $\mu_{f}$ and $\rho_{f}$ stand for dynamic viscosity and density of the base liquid, $K_{s}$ for thermal conduction of substantial nano subdivisions, $K_{n f}$ for thermal conduction of nanoparticle-based fluid and $K_{f}$ for thermal conduction of the base liquid. The corresponding boundary conditions are:

$$
\begin{aligned}
& \bar{u}_{1}=a x, \bar{u}_{2}=0, \bar{u}_{3}=0 \text { at } z=0, \\
& \bar{u}_{1} \rightarrow 0, \bar{u}_{2}=0 \quad \text { as } z \rightarrow \infty, \\
& T=T_{w} \quad \text { at } z=0, \\
& T \rightarrow T_{\infty} \quad \text { as } z \rightarrow \infty .
\end{aligned}
$$

Here " $a$ " stands for the proportionality constant of enlarging rate of plane $z=0$ directing to $x$-axis, $T_{w}$ for temperature of plane $z=0$ and $T_{\infty}$ for the temperature of the free stream. The transforming relations are:

$$
\begin{aligned}
& \bar{u}_{1}=a x f^{\prime}(\eta), \bar{u}_{2}=\operatorname{axh}(\eta), \bar{u}_{3}=-\sqrt{a v} f(\eta), \\
& \eta=z \sqrt{\frac{a}{v}}, \quad \theta(\eta)=\frac{T-T_{\infty}}{T_{w}-T_{\infty}} .
\end{aligned}
$$

Here, symbols $f^{\prime}(\eta)$, and $f(\eta)$ stand for dimensionless velocity parts. Using Eqs. (6) and (8), Eq. (1) is identically satisfied and Eqs. (2)-(5), after simplification, take the shape as:

$$
\begin{aligned}
& f^{\prime \prime \prime}+(1-\varphi)^{2.5}\left\{\left(1+\varphi \frac{\rho_{s}}{\rho_{f}}-\varphi\right)\left(f f^{\prime \prime}-f^{\prime} f^{\prime}+2 h \lambda\right)\right. \\
&-\left.f^{\prime} M^{2}\right\}=0 \\
& h^{\prime \prime}+(1-\varphi)^{2.5}\left\{\left(1+\varphi \frac{\rho_{s}}{\rho_{f}}-\varphi\right)\left(f h^{\prime}-h f^{\prime}-2 f^{\prime} \lambda\right)\right. \\
&\left.-h M^{2}\right\}=0, \\
& \theta^{\prime \prime}+\operatorname{Pr} \frac{K_{f}}{K_{n f}}\left\{\left(1+\varphi \frac{\left(C_{p} \rho\right)_{s}}{\left(C_{p} \rho\right)_{f}}-\varphi\right)\left(f \theta^{\prime}-2 f^{\prime} \theta\right)\right. \\
&\left.+\frac{\mathrm{Ec}}{(1-\varphi)^{2.5}}\left[f^{\prime \prime 2}+h^{\prime 2}\right]\right\}=0 .
\end{aligned}
$$

Here, $\operatorname{Pr}=\frac{\left(\mu C_{p}\right)_{f}}{K_{f}}$ stands for Prandtl number, Ec for Eckert number, $\lambda$ for non-dimensional rotation factor and $M$ for magnetic factor, and are given by:

$$
\mathrm{Ec}=\frac{u^{2}}{c_{p}\left(T_{w}-T_{\infty}\right)}, \quad M=\sqrt{\frac{\sigma_{n f}}{a \rho_{f}}} B_{0} .
$$

Here, for the substantial volume percent fraction of nano subdivisions $\varphi=0$ and for magnetic parameter $M=0$ above, Eqs. (9) and (10) become identical with those of Wang [55]. Using similarity transformations (8), end value conditions (7) are disguised as: 


$$
\begin{aligned}
& f=0, \quad h=0, \quad f^{\prime}=1, \theta=1 \quad \text { at } \eta=0, \\
& h=0, \quad f^{\prime}=0, \quad \theta=0 \quad \text { as } \eta \rightarrow \infty .
\end{aligned}
$$

\section{Solution process}

A non-linear system of differential Eqs. (9)-(11) with end point constraints (13) are integrated using a reliable procedure termed as the mid-point numerical scheme, with the extrapolation of Richardson as an enhancer. The Richardson extrapolation scheme uses two estimates of an integral to compute a third more accurate approximation. This is presented by several other authors $[52,53]$. Since it is not convenient to solve the system on a semi-infinite domain, the problem is solved on a suitable finite domain of $\eta$ and infinite limit $\eta_{\infty}$ is replaced by a finite limit $\eta_{\infty}=6$. A mesh size 0.0001 is considered as appropriate to extract an accuracy up to $10^{-8}$ in our results. The detailed algorithm of the applied numerical scheme can be found in [52-54]. A symbolic computational mathematical software Maple has been used to perform graphical outputs as well as numerical tabulations. The authors core interest is to compute the numerical values of tangential stress and Nusselt number under various conditions.

$$
\begin{aligned}
& C f_{x}=\frac{\tau_{x z}}{\rho(a x)^{2}}, \quad C f_{y}=\frac{\tau_{y z}}{\rho(a x)^{2}}, \\
& N u=\frac{x q_{w}}{K_{f}\left(T_{w}-T_{\infty}\right)} .
\end{aligned}
$$

Definitions of $q_{w}, \tau_{y z}$, and $q_{w}$ are as:

$$
\begin{aligned}
\tau_{x z} & =\mu_{n f}\left(\frac{\partial \bar{u}_{1}}{\partial z}+\frac{\partial \bar{u}_{3}}{\partial z}\right)_{z=0}, \\
\tau_{y z} & =\mu_{n f}\left(\frac{\partial \bar{u}_{2}}{\partial z}+\frac{\partial \bar{u}_{3}}{\partial z}\right)_{z=0}, \\
q_{w} & =-K_{n f}\left(\frac{\partial T}{\partial z}\right)_{z=0} .
\end{aligned}
$$

Using Eq. (15) together with Eq. (6) in Eq. (14), we get:

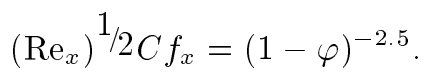

The symbol $\operatorname{Re}_{x}=\left(\frac{\bar{u}_{1 w}}{v_{f}}\right)$ stands for locally born Reynolds number and $\mathrm{Nu}$ for Nusselt number. The essential physical measures confined to our case have been computed in Table 1.

\section{Discussions}

This subdivision of study is dedicated to discovering the impact of relevant parameters as solid nanoparticle $\varphi$, magnetic factor $M$, rotation factor $\lambda$ and Eckert number Ec on the speed and temperature of fluid. Water and kerosene liquids have been used as base fluids in this study with substantial nano subdivisions of $\mathrm{BaO} .6 \mathrm{Fe}_{2} \mathrm{O}_{3}$ (barium ferrite ferromagnetic particles). Figures $1-5$ are constructed to analyse the effects of various factors on the temperature and movement of the liquid. Due to Ferro nano subdivisions $\mathrm{BaO} .6 \mathrm{Fe}_{2} \mathrm{O}_{3}$, both liquids are called Ferro fluids. Figure 1(a) to (d) are computed to look into variations due to magnetic factor $M$ plus spin factor $\lambda$ on speed $f^{\prime}(\eta)$ for both Ferro fluids. Figure 1(a) and (b) infer that without a magnetic field, an inclusion of nano particles decreases the velocity of both fluids, while with the magnetic field, the inclusion of some nano particles gears up the non-dimensional fluid velocity. Physically, it may be interpreted as nano particles are massive and, hence, their inclusion in base fluids gears down the fluid velocity, but, the existence of a fixed amount of magnetic field gears up the speed of nano subdivisions and, hence, fluid velocity increases. It is interesting to note that an improvement in the magnitude of magnetic factor $M$ implies a decrease in velocity $f^{\prime}(\eta)$ for both nanoparticle-based fluids. Retarding Lorentz forces are the only cause of this fall in velocity. Similarly, in Figure 1(c) and (d), when the magnetic field is fixed, we observe that a rise in spin factor $\lambda$ implies a fall in the linear rate of displacement $f^{\prime}(\eta)$. Physical interpretation is that the linear velocity $f^{\prime}(\eta)$ along $x$-axis is interrupted by angular velocity and hence decreases. The immediate increase of massive nano particles obviously declines the linear velocity profile $f^{\prime}(\eta)$. This fact is more apparent

Table 1. Thermo physical properties of base fluids and nanoparticles [40,44].

\begin{tabular}{cccc}
\hline Properties/constituents & Water & Kerosene oil & Barium ferrite \\
\hline Density $\rho\left(\mathrm{kg} / \mathrm{m}^{3}\right)$ & 997.1 & 783 & 5280 \\
Specific Heat $C_{p}(\mathrm{~J} / \mathrm{kg} . \mathrm{K})$ & 4179 & 2090 & 650 \\
Thermal Conductivity, $K(\mathrm{~W} / \mathrm{m} . \mathrm{K})$ & 0.613 & 0.15 & $300-330$ \\
Prandtl number & 6.2 & 21 & - \\
\hline
\end{tabular}




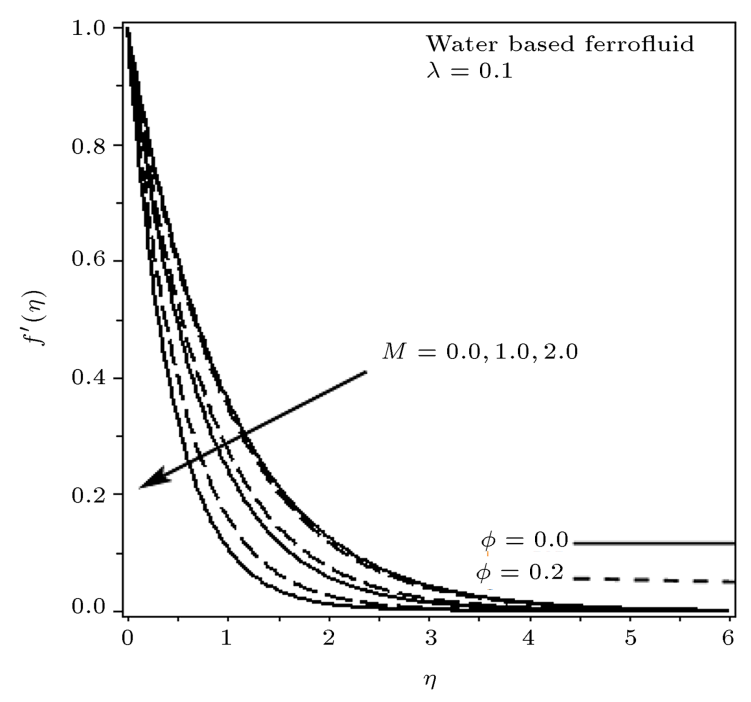

(a)

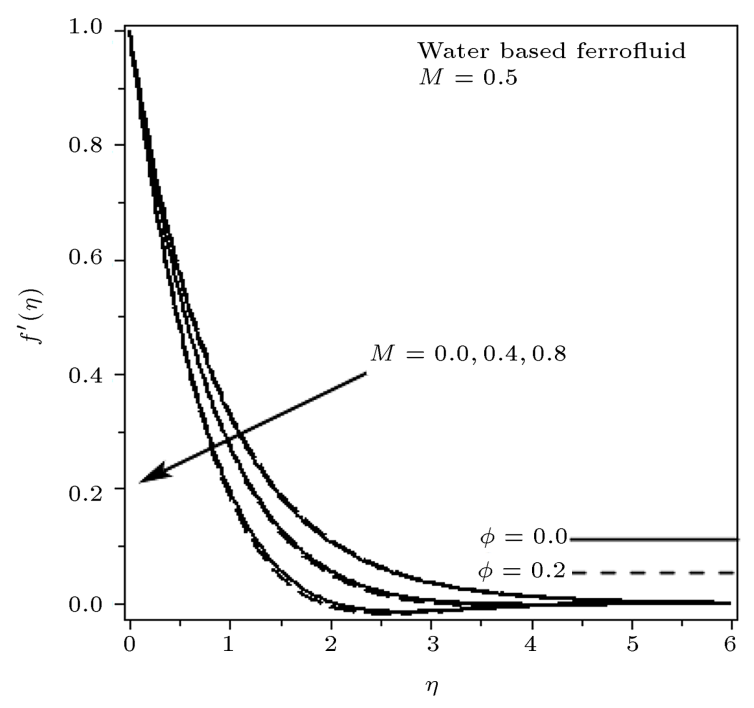

(c)

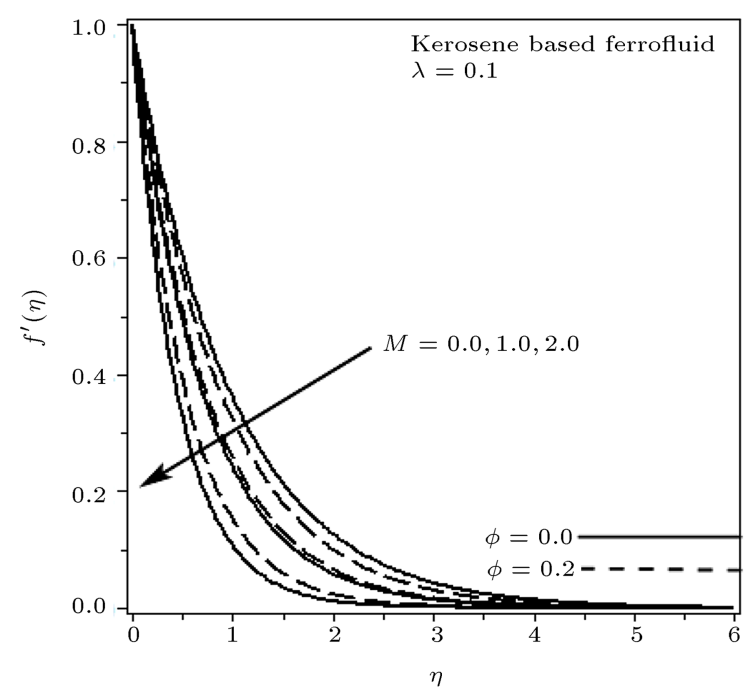

(b)

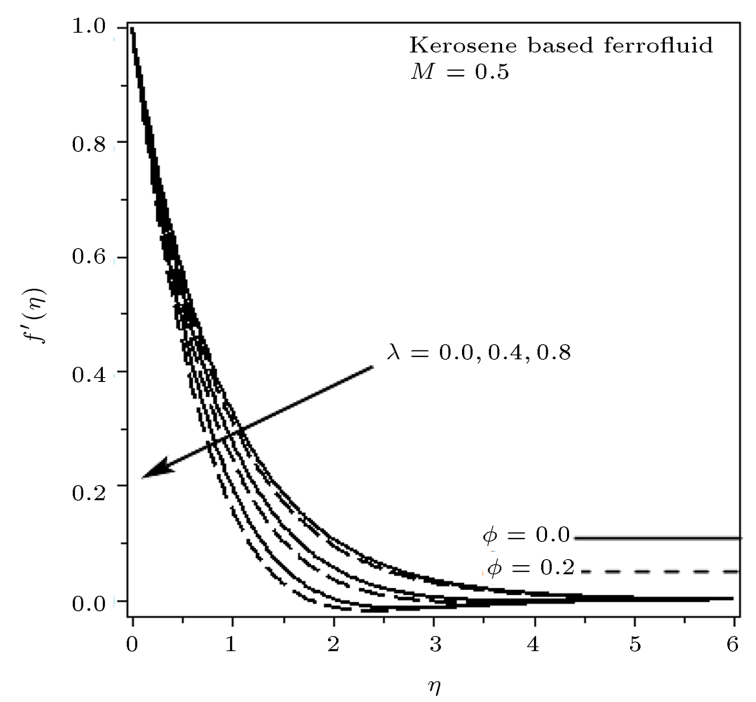

(d)

Figure 1. Effects of magnetic parameter $M$ and rotation parameter $\lambda$ on velocity $f(\eta)$ for water based and kerosene based fluids.

for kerosene based liquid. Variations in velocity $h(\eta)$ because of magnetic factor $M$ and spin factor $\lambda$ are apparent from Figure 2(a) to (d). As the fluid motion is only due to the stretching along the $x$-axis, the nondimensional fluid velocity $h(\eta)$ first reduces negatively down to a definite limit of $\eta$ and subsequently rises. Here, rotation declines the linear velocity $h(\eta)$, while the magnetic field gears up the linear velocity due to 5its direction normal to that of the motion of nano particles. The impact of magnetism and spin on normal rate of displacement $f(\eta)$ for nanoparticle-based fluids is exposed by Figure 3(a) to (d). Figure 3(a) and (b) reveal that a rise in magnetic factor $M$ implies a significant fall in displacement rate $f(\eta)$. It is observed that the non-dimensional velocity of fluid $f(\eta)$ rapidly increases in the boundary layer near the surface $z=0$ up to a certain height of non-dimensional variable $\eta$ and becomes uniform beyond this layer. The reason is that the fluid motion is only due to the stretching of surface $z=0$ in the direction of the $x$-axis. Figure $3(\mathrm{c})$ and $(\mathrm{d})$ are designed to determine variations on $f(\eta)$ due to spin factor $\lambda$. Noticeably, for either of the fluids growing spin gears down the linear displacement rate $f(\eta)$. It is apparent that kerosene related fluid is more respondent in view of velocity $f(\eta)$ than water related fluid. Figure $4(\mathrm{a})$ to $(\mathrm{d})$ are drawn to check the impact of magnetic factor $M$ and spin factor $\lambda$ on temperature $\theta(\eta)$ for both Ferro fluids. A firsthand view depicts that temperature $\theta(\eta)$ rises with a rise in either rotational velocity parameter $\lambda$ or substantial nano subdivision percent volume fraction $\varphi$. The physical interpretation reveals that an increase 


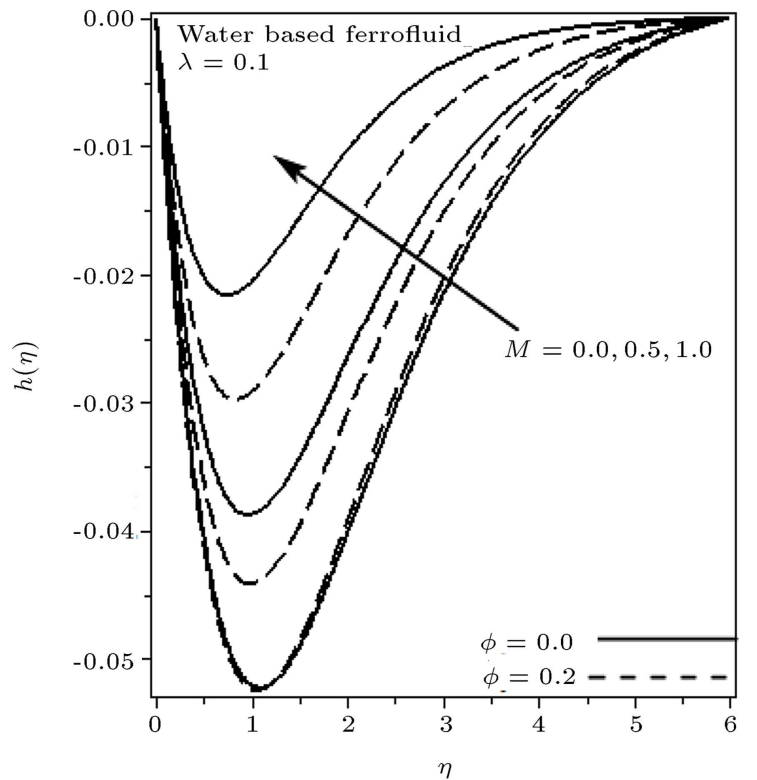

(a)

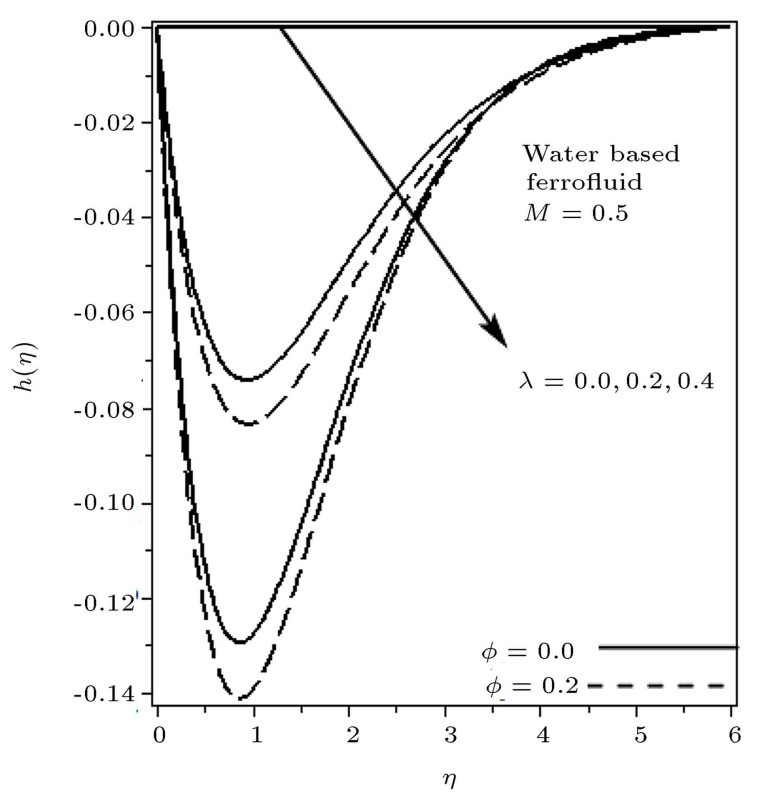

(c)

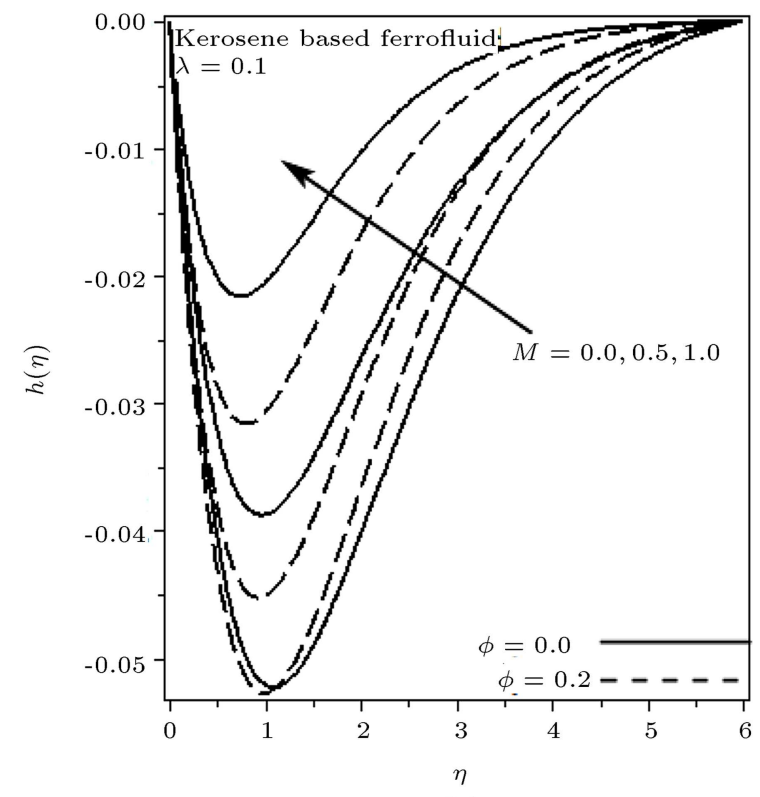

(b)

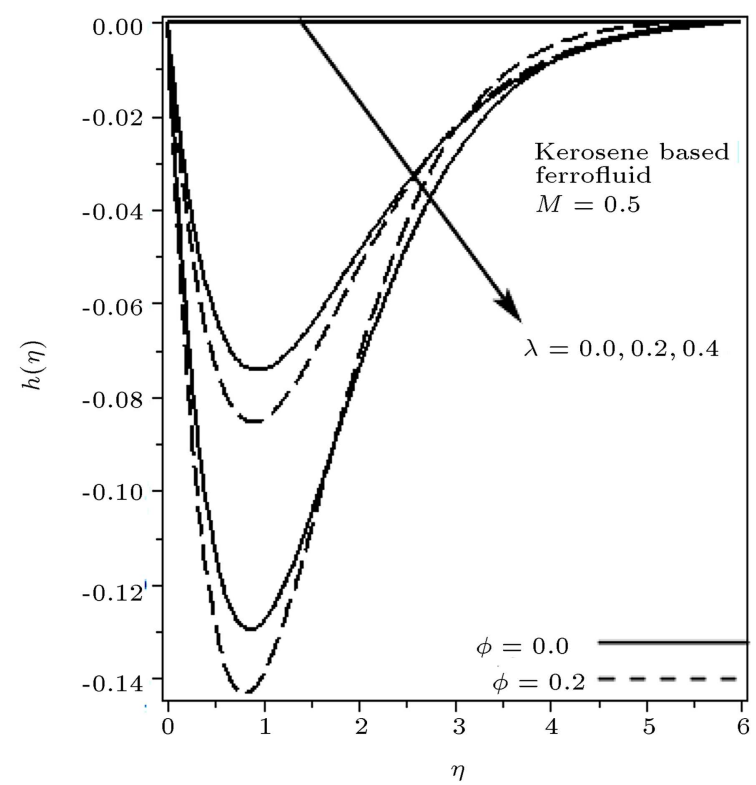

(d)

Figure 2. Effects of magnetic parameter $M$ and rotation parameter $\lambda$ on velocity $h(\eta)$ for water based and kerosene based fluids.

in either of these two parameters increases the collision of nano particles and, hence, temperature is increased. Also, a rise in magnetic factor $M$ boosts Lorentz forces causing a delay in flow which results in a growth in the temperature profile. Figure 5(a) and (b) illustrate the impact of substantial nano subdivision percent volume fraction $\varphi$, magnetic factor $M$ plus rotation parameter $\lambda$ on tangential stress $(1-\varphi)^{-2.5} f^{\prime \prime}(0)$. Each of these parameters improves tangential stress for both Ferro fluids. The reason is that enhancement of any of these three parameters means an enhancement in the collision of nano particles, hence, a greater collision with the wall and ultimately a rise in skin friction is observed. Figure $5(\mathrm{c})$ and $(\mathrm{d})$ provide variations in heat transfer rate $-\left(K_{n f} / K_{f}\right) \theta^{\prime}(0)$ due to Eckert number Ec, substantial nano subdivision percent volume fraction $\varphi$, magnetic factor $M$ and spin factor $\lambda$. Figure 5(c) and (d) show that a rise in $\varphi$ implies a rise in heat transfer rate at the ground level as more inclusion of $\varphi$ means more collision between particles and, hence, more heat per unit surface is produced, whereas a decay in heat transfer rate is 


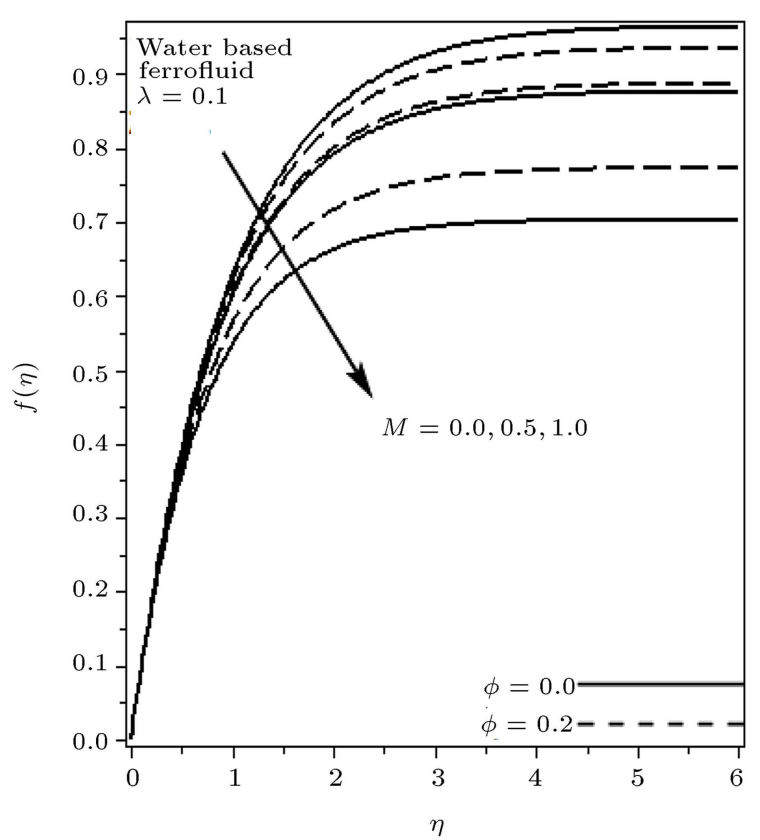

(a)

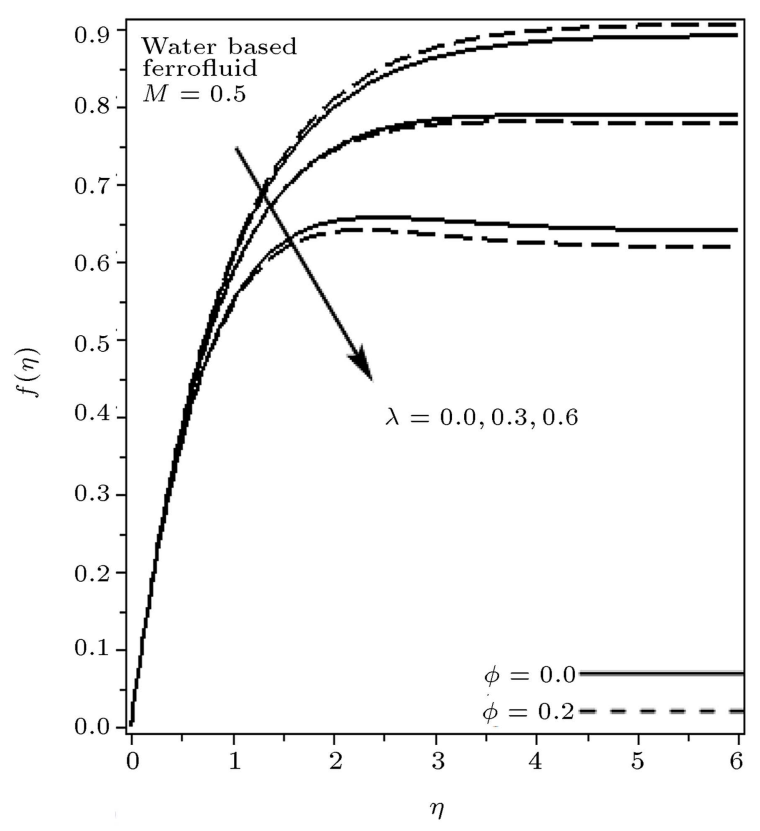

(c)

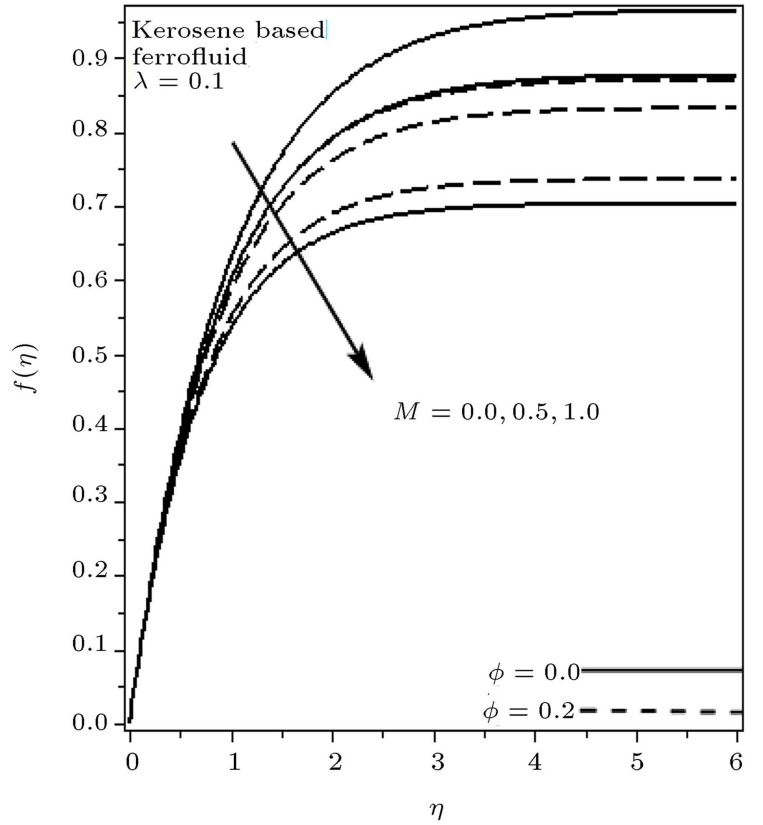

(b)

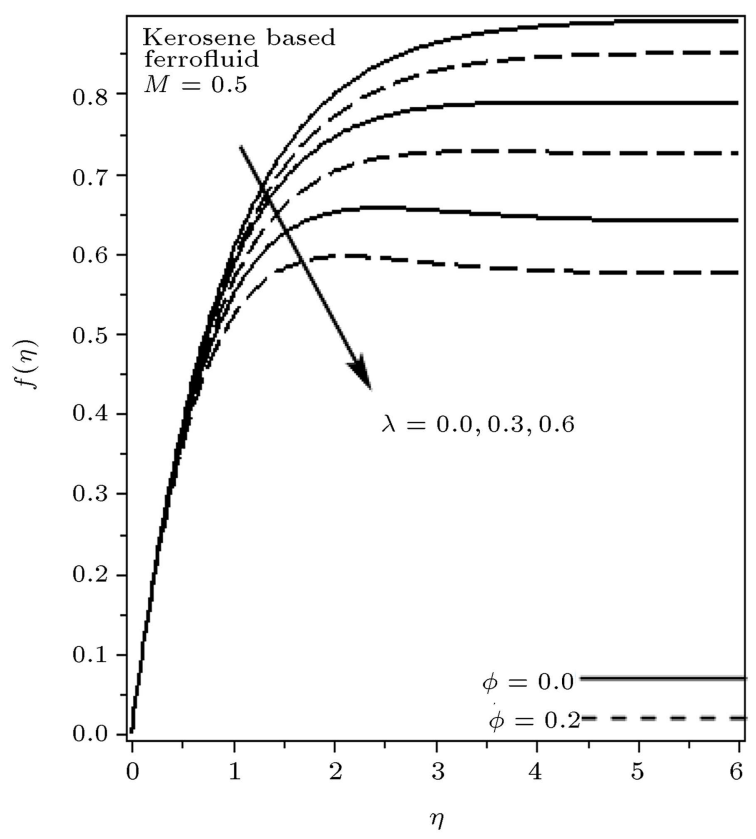

(d)

Figure 3. Effects of magnetic parameter $M$ and rotation parameter $\lambda$ on velocity $f^{\prime}(\eta)$ for water based and kerosene based fluids.

observed due to each of three factors $M$, Ec and $\lambda$. It is noticeable that Kerosene based liquid shows evident results because of the high Prandtl number of kerosene.

Besides graphs, results are also extracted by computing tables. Table 1 includes some fixed possessions of quantities employed in this study. Table 2 elaborates that the addition of a substantial nano subdivision percent volume fraction $\varphi$ causes an addition in tangential stress $(1-\varphi)^{-2.5} f^{\prime \prime}(0)$ as well as in heat transfer rate $-\left(K_{n f} / K_{f}\right) \theta^{\prime}(0)$. These tabular results are compatible with those extracted from Figure $5(\mathrm{a})$ to (d). Physically, the result agrees as more massive nano particles in liquid implies further collision between themselves and the surface and, hence results in more tangential stress and heat transmission rate at ground level. It is noticeable that an addition in magnetic factor $M$ implies an absolute addition in tangential 


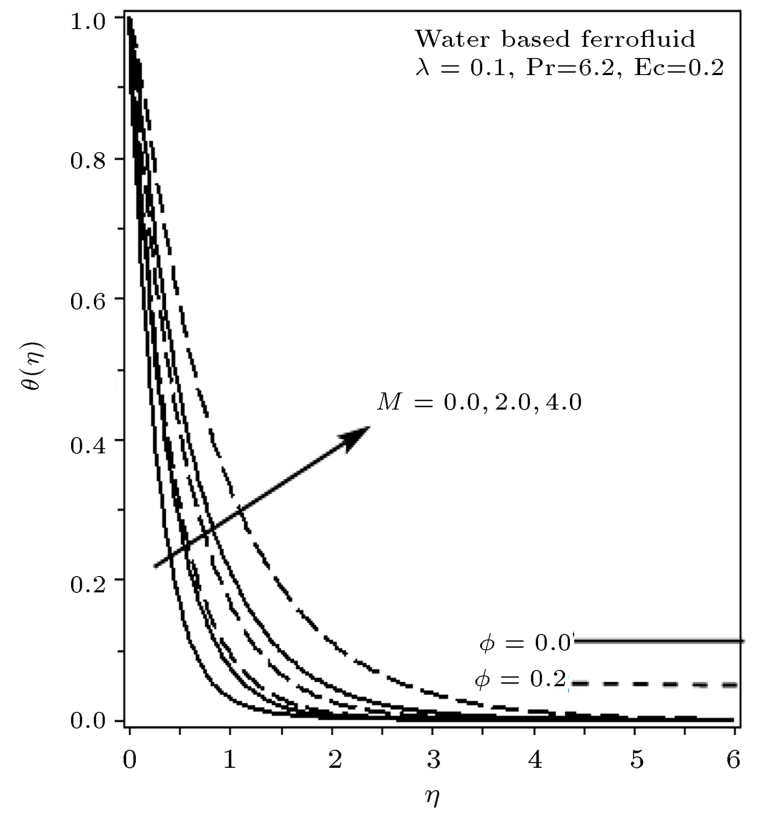

(a)

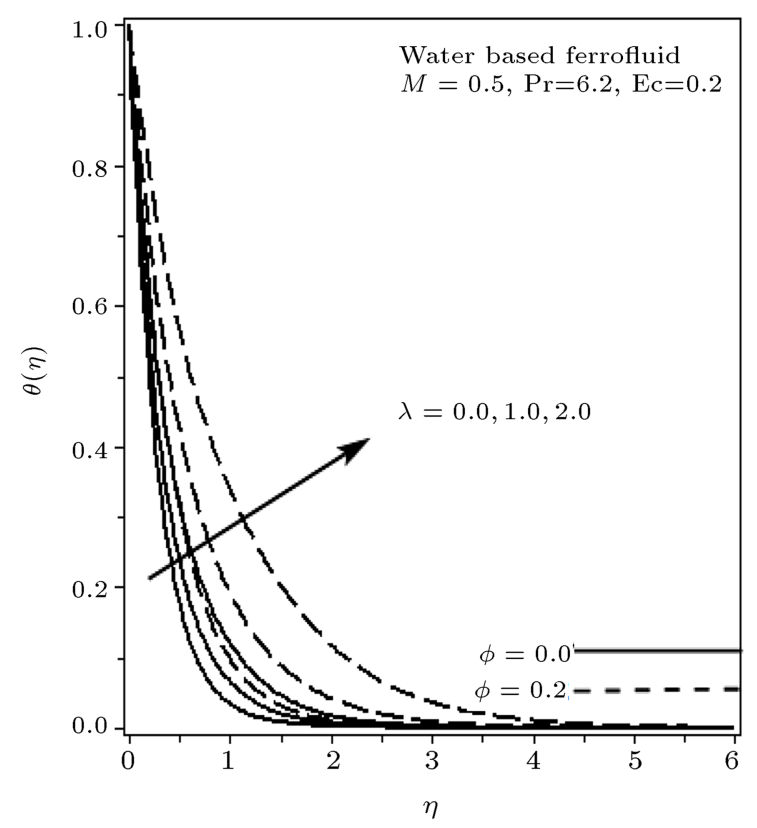

(c)

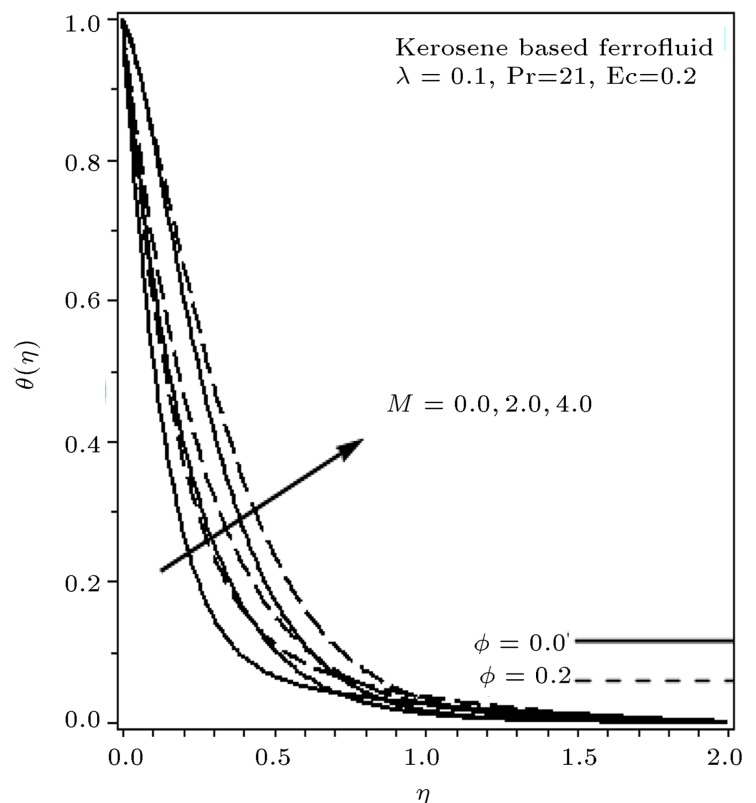

(b)

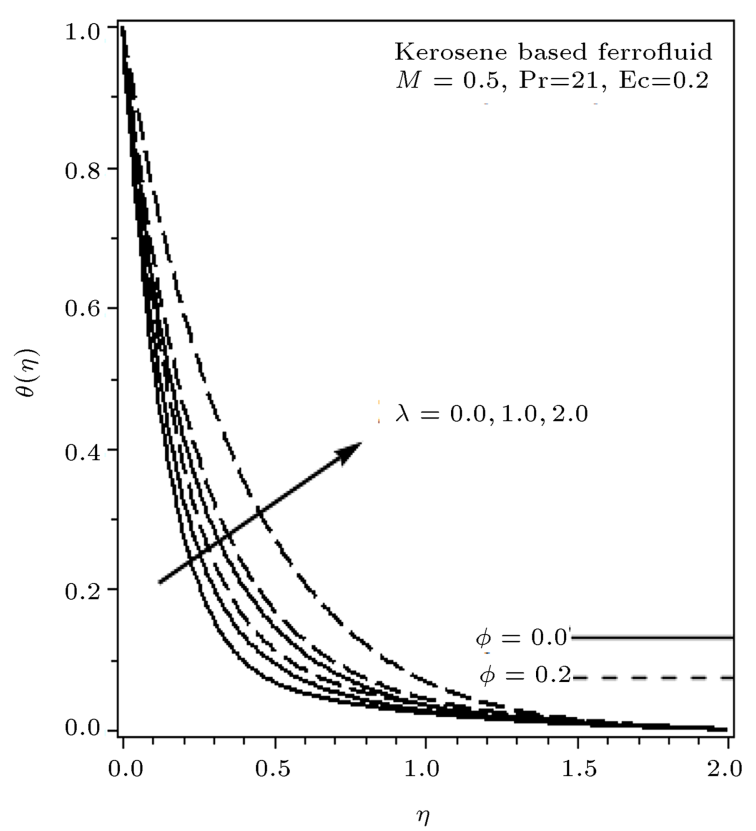

(d)

Figure 4. Effects of magnetic parameter $M$ and rotation parameter $\lambda$ on temperature $\theta(\eta)$ for water based and kerosene based fluids.

stress $(1-\varphi)^{-2.5} f^{\prime \prime}(0)$ together with an ultimate fall in heat transmission rate $-\left(K_{n f} / K_{f}\right) \theta^{\prime}(0)$. These numerical results again agree with pictorial results in Figure 5(a), (b), and (c). Here, kerosene based liquid once again shows evident results due to its high Prandtl number, indicating the significance of the selection of fluid type. Further, an addition in spin factor $\lambda$ produces an addition in local tangential stress but a subtraction in heat transmission rate. Again, the outputs coincide with those of graphical outputs. In Table 3, a contrast between tangential stresses plus the heat transmission rates of this study are already observed in published works of some researchers and a satisfactory match is observed. In Table 4, heat transmission rates at ground level $(z=0)$ for $\varphi=0$ have been calculated for some values of Prandtl number Pr and spin factor $\lambda$.

\section{Final remarks}

MHD ferrofluid over a stretching surface is considered in this study. The comparison of two fluids 


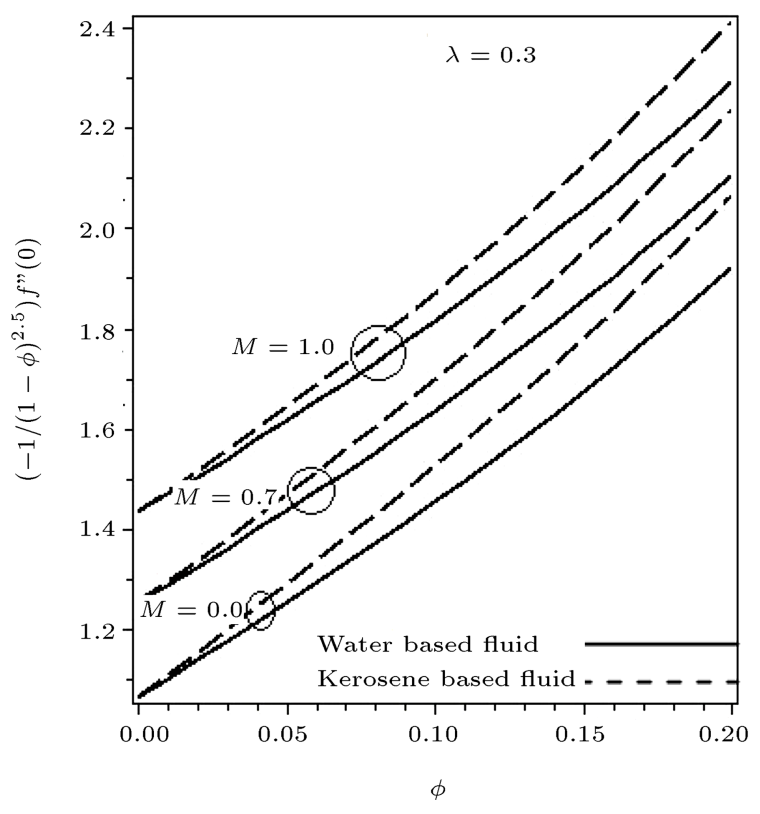

(a)

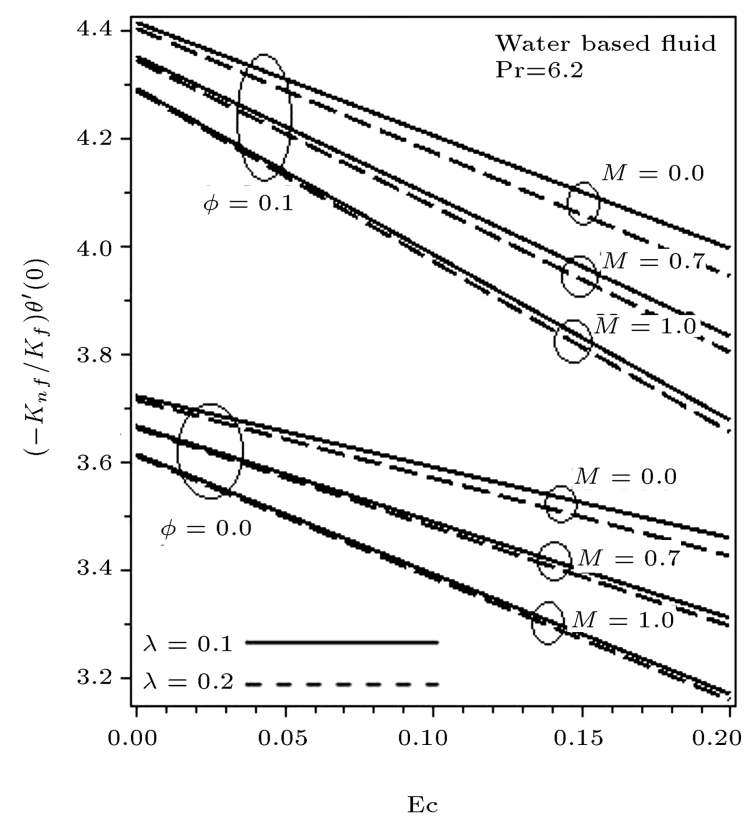

(c)

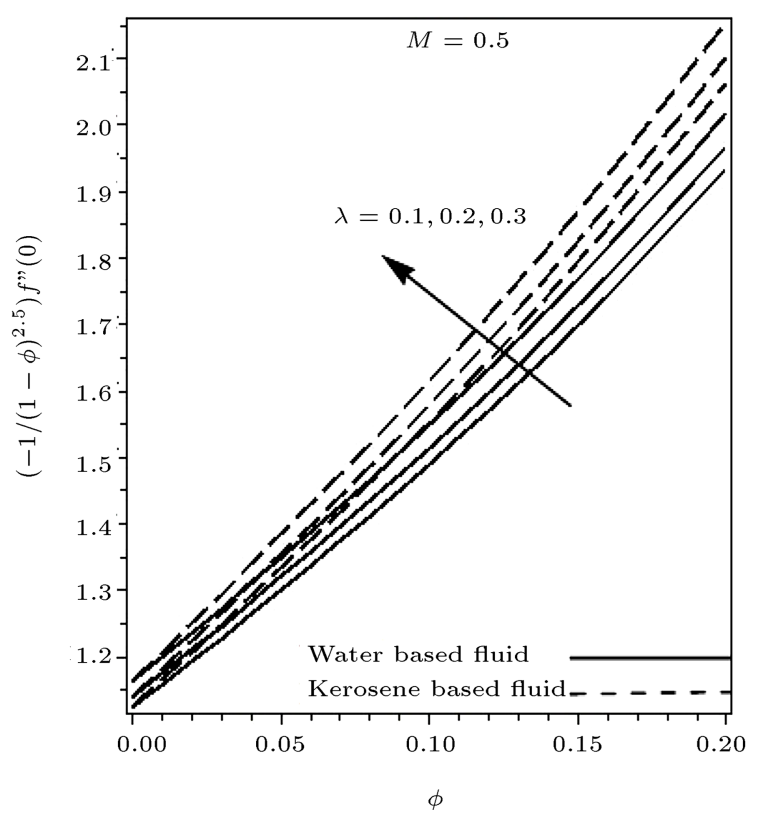

(b)

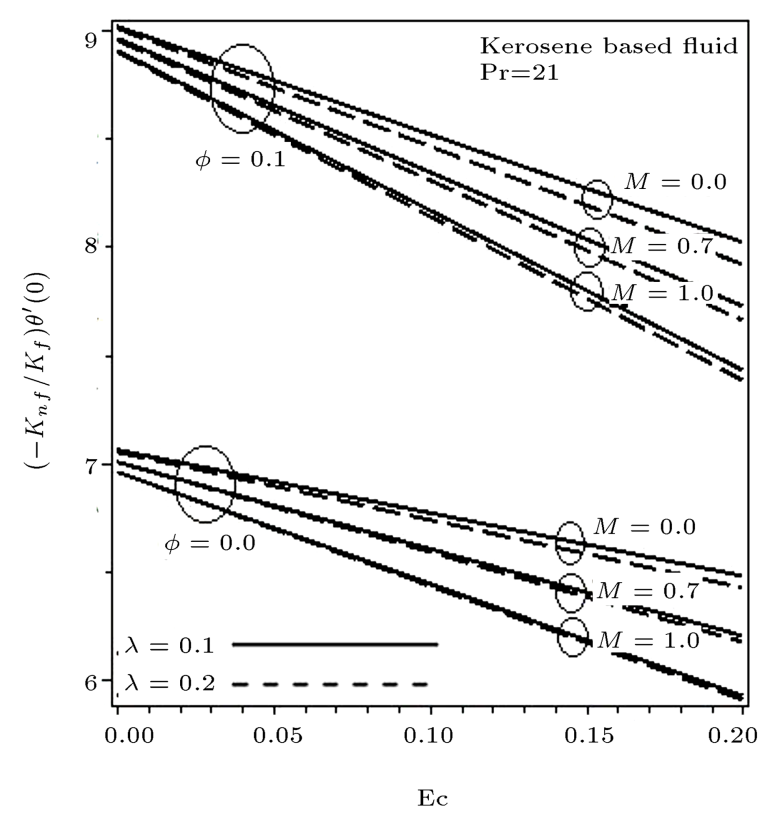

(d)

Figure 5. Effects of $M, \lambda, \varphi$ and Eckert number Ec on skin friction.

are discussed, $\mathrm{BaO} .6 \mathrm{Fe}_{2} \mathrm{O}_{3}$-water and $\mathrm{BaO} .6 \mathrm{Fe}_{2} \mathrm{O}_{3}$ kerosene, using viscous dissipation and slip effects. The presented results are summarized as below:

- Magnetic factor $M$ and spin factor $\lambda$ decline the linear velocity of water-based and kerosene-based fluids;

- Improving the values of solid nanoparticles decelerates the flow, but the existence of a magnetic field accelerates the flow;
- Magnetic factor $M$ and spin factor $\lambda$ boost the temperature of both nanoparticle-based fluids;

- Proliferation in either magnetic factor $M$, spin factor $\lambda$ or solid nanoparticle $\varphi$ implies a proliferation in tangential stress. Higher skin friction is recorded for kerosene grounded fluid;

- Heat transfer rate at surface level $z=0$ rises with a rise in solid nanoparticle $\varphi$, but falls with a rise in magnetic factor $M$, spin factor $\lambda$ and Eckert number 
Table 2. Effects of $\varphi, \lambda$ and $M$ on $-(1-\varphi)^{-2.5} f^{\prime \prime}(0)$ and $-K_{n f}\left(K_{f}\right)^{-1} \theta^{\prime}(0)$ for $(\mathrm{Ec}=0.20)$.

\begin{tabular}{|c|c|c|c|c|c|c|}
\hline \multirow[t]{2}{*}{$\begin{array}{c}\text { Particle } \\
\text { volume } \\
\text { fraction, } \varphi\end{array}$} & \multirow[t]{2}{*}{$\begin{array}{l}\text { Spin } \\
\text { factor } \\
\lambda\end{array}$} & \multirow[t]{2}{*}{$\begin{array}{c}\text { Magnetic } \\
\text { parameter } \\
M\end{array}$} & \multicolumn{2}{|c|}{$\begin{array}{l}\text { Water based ferrofluid } \\
\qquad \operatorname{Pr}=6.2\end{array}$} & \multicolumn{2}{|c|}{$\begin{array}{c}\text { Kerosene based ferrofluid } \\
\qquad \operatorname{Pr}=21\end{array}$} \\
\hline & & & $-(1-\varphi)^{-2.5} f^{\prime \prime}(0)$ & $-\left(\boldsymbol{K}_{n f} / \boldsymbol{K}_{f}\right) \boldsymbol{\theta}^{\prime}(\mathbf{0})$ & $-(1-\varphi)^{-2.5} f^{\prime \prime}(0)$ & $-\left(K_{n f} / K_{f}\right) \theta^{\prime}(0)$ \\
\hline 0.00 & \multirow{4}{*}{0.10} & \multirow{4}{*}{2.0} & 2.236559 & 2.507957 & 2.236559 & 4.573644 \\
\hline 0.05 & & & 2.435554 & 2.698778 & 2.452457 & 5.197406 \\
\hline 0.10 & & & 2.659187 & 2.908047 & 2.694583 & 5.909684 \\
\hline 0.15 & & & 2.912350 & 3.144306 & 2.968151 & 6.740613 \\
\hline \multirow{4}{*}{0.10} & \multirow{4}{*}{0.20} & 0.0 & 1.409090 & 3.944086 & 1.478730 & 7.922196 \\
\hline & & 0.5 & 1.511260 & 3.871845 & 1.576232 & 7.790811 \\
\hline & & 1.0 & 1.794534 & 3.652673 & 1.848817 & 7.383446 \\
\hline & & 1.5 & 2.196177 & 3.315605 & 2.240073 & 6.730525 \\
\hline \multirow{4}{*}{0.20} & 0.00 & \multirow{4}{*}{1.0} & 2.234858 & 4.343445 & 2.345310 & 9.510975 \\
\hline & 0.10 & & 2.241574 & 4.330034 & 2.353242 & 9.481600 \\
\hline & 0.20 & & 2.260911 & 4.291290 & 2.375943 & 9.397217 \\
\hline & 0.30 & & 2.290830 & 4.230960 & 2.410732 & 9.267064 \\
\hline
\end{tabular}

Table 3. Contrast of tangential stresses $f^{\prime \prime}(0), h^{\prime}(0)$ for viscous fluid $\varphi=0=M$.

\begin{tabular}{ccccccccc}
\hline $\boldsymbol{\lambda}$ & \multicolumn{2}{c}{ Wang [55] } & \multicolumn{2}{c}{ Kumari and Nath [42] } & \multicolumn{2}{c}{ Nadeem et al. [56] } & \multicolumn{2}{c}{ Present results } \\
\hline & $f^{\prime \prime}(0)$ & $h^{\prime}(0)$ & $f^{\prime \prime}(0)$ & $h^{\prime}(0)$ & $f^{\prime \prime}(0)$ & $h^{\prime}(0)$ & $f^{\prime \prime}(0)$ & $h^{\prime}(0)$ \\
\cline { 2 - 9 } 0.00 & 1.000 & 0.000 & 1.000 & 0.000 & 1.000 & 0.000 & 1.000 & 0.000 \\
0.50 & 1.138 & 0.513 & 1.138 & 0.513 & 1.138 & 0.513 & 1.138 & 0.513 \\
1.00 & 1.325 & 0.837 & 1.325 & 0.837 & 1.325 & 0.837 & 1.325 & 0.837 \\
2.00 & 1.652 & 1.287 & 1.654 & 1.287 & 1.652 & 1.287 & 1.652 & 1.287 \\
\hline
\end{tabular}

Table 4. Some values of $\theta^{\prime}(0)$ for viscid fluid $\varphi=0=M$, $\mathrm{Ec}=10$.

\begin{tabular}{ccccc}
\hline $\mathbf{P r}$ & $\boldsymbol{\lambda}=\mathbf{0 . 0}$ & $\boldsymbol{\lambda}=\mathbf{1 . 0}$ & $\boldsymbol{\lambda}=\mathbf{2 . 0}$ & $\boldsymbol{\lambda}=\mathbf{3 . 0}$ \\
\hline 0.70 & 1.044 & 0.799 & 0.602 & 0.481 \\
2.00 & 1.943 & 1.704 & 1.416 & 1.174 \\
6.00 & 3.533 & 3.251 & 2.922 & 2.604 \\
\hline
\end{tabular}

Ec. The higher heat transfer rate is recorded in the case of kerosene grounded Ferro fluid;

- Base fluid plays a vital role in determinations. Water is preferred as a base fluid for significant outcomes.

\section{Nomenclature}

$\begin{array}{ll}a & \text { Stretching rate } \\ C_{f x} & \text { Tangential stress parallel to } x \text {-axis } \\ C_{f y} & \text { Tangential stress parallel to } y \text {-axis } \\ C_{p} & \text { Specific heat }\end{array}$

Ec Eckert number

$M \quad$ Magnetic field

$\mathrm{Nu} \quad$ Nusselt number

Pr Prandtl number

$K_{f} \quad$ Thermal conductions of base fluid

$K_{s} \quad$ Thermal conductions of solid particle

$K_{n f} \quad$ Thermal conductions of nanofluid

$\mu_{f} \quad$ Dynamic viscosity of base fluid

$\mu_{n f} \quad$ Dynamic viscosity of nanofluid

$\sigma_{f} \quad$ Electrical conductivity of base fluid

$\sigma_{n f} \quad$ Electrical conductivity of nanofluid

$\left(C_{p}\right)_{f} \quad$ Heat capacity of base fluid

$\left(C_{p}\right)_{s} \quad$ Heat capacity of solid nanoparticle

$T \quad$ Fluid temperature

$T_{\infty} \quad$ Free stream temperature

$T_{w} \quad$ Wall temperature

$x, y, z \quad$ Cartesian coordinates 


$\begin{array}{ll}\eta & \text { Dimensionless space variable } \\ \theta & \text { Temperature profile } \\ \varphi & \text { Solid nanoparticle friction } \\ \lambda & \text { Spin factor } \\ \Omega & \text { Angular speed } \\ \rho_{f} & \text { Density of base fluid } \\ \rho_{s} & \text { Density of solid nanoparticle } \\ \rho_{n f} & \text { Density of nanofluid } \\ v_{f} & \text { Kinematic viscosity of base fluid } \\ v_{n f} & \text { Kinematic viscosity of nanofluid } \\ \sigma_{f} & \text { Thermal diffusivity of base fluid } \\ \alpha_{n f} & \text { Thermal diffusivity of nanofluid } \\ \left(C_{p}\right)_{n f} & \text { Heat capacity of nanofluid }\end{array}$

\section{References}

1. Choi, S.U.S. and Eastman, J.A. "Enhancing thermal conductivity of fluids with nanoparticles", No. ANL/MSD/CP-84938; CONF-951135-29, Argonne National Lab., IL United States (1995).

2. Lee, S. and Choi, S.U.S. "Application of metallic nanoparticle suspensions in advanced cooling systems", Recent Advance in Solids/Structures and Application of Metallic Materials, ASME MD-72, 234, p. 227 (1996).

3. Pak, B.C. and Cho, Y.I. "Hydrodynamic and heat transfer study of dispersed fluids with submicron metallic oxide particles", Experimental Heat Transfer an International Journal, 11(2), pp. 151-170 (1998).

4. Wang, X., Xu, X., and Choi, S.U.S. "Thermal conductivity of nanoparticle-fluid mixture", Journal of Thermophysics and Hat Transfer, 13(4), pp. 474-480 (1999).

5. Li, Q. and Xuan, Y. "Experimental investigation of transport properties of nanofluids", Heat Transfer Science and Technology, 2000, pp. 757-762 (2000).

6. Buongiorno, J. "Convective transport in nanofluids", J. Heat Transfer, 128(3), pp. 240-250 (2006).

7. Kakaç, S. and Pramuanjaroenkij, A. "Review of convective heat transfer enhancement with nanofluids", International journal of Heat and Mass Transfer, 52(13-14), pp. 3187-3196 (2009).

8. Xuan, Y. "Conception for enhanced mass transport in binary nanofluids", Heat and Mass Transfer, 46(2), pp. 277-279 (2009).

9. Wong, K.F.V. and Leon, O.D. "Applications of nanofluids: current and future", Advances in Mecha Engineering, 2010, Article ID 519659, pp. 1-11 (2010).

10. Avramenko, A.A., Shevchuk, I.V., Tyrinov, A.I., and Blinov, D.G. "Heat transfer at film condensation of stationary vapor with nanoparticles near a vertical plate", Applied Thermal Engineering, 73(1), pp. 391398 (2014).
11. Avramenko, A.A., Shevchuk, I.V., Tyrinov, A.I., and Blinov, D.G. "Heat transfer in stable film boiling of a nanofluid over a vertical surface", International Journal of Thermal Sciences, 92, pp. 106-118 (2015).

12. Avramenko, A.A., Shevchuk, I.V., Tyrinov, A.I., and Blinov, D.G. "Heat transfer at film condensation of moving vapor with nanoparticles over a flat surface", International Journal of Heat and Mass Transfer, 82, pp. 316-324 (2015).

13. Ahmed, Z., Nadeem, S., Saleem, S., and Ellahi, R. "Numerical study of unsteady flow and heat transfer CNT-based MHD nanofluid with variable viscosity over a permeable shrinking surface", International Journal of Numerical Methods for Heat \& Fluid Flow, 29(12), pp. 4607-4623 (2019).

14. Avramenko, A.A. and Shevchuk, I.V. "Lie group analysis and general forms of self-similar parabolic equations for fluid flow, heat and mass transfer of nanofluids", Journal of Thermal Analysis and Calorimetry, 135(1), pp. 223-235 (2019).

15. Nazari, S., Ellahi, R., Sarafraz, M.M., Safaei, M.R., Asgari, A., and Akbari, O.A. "Numerical study on mixed convection of a non-Newtonian nanofluid with porous media in a two lid-driven square cavity", Journal of Thermal Analysis and Calorimetry, 140, pp. 1121-1145 (2019).

16. Ellahi, R., Sait, S.M., Shehzad, N., and Ayaz, Z. "A hybrid investigation on numerical and analytical solutions of electro-magnetohydrodynamics flow of nanofluid through porous media with entropy generation", International Journal of Numerical Methods for Heat and Fluid Flow, 30(2), pp. 834-854 (2019).

17. Ellahi, R., Hussain, F., Abbas, S.A., Sarafraz, M.M., Goodarzi, M., and Shadloo, M.S. "Study of twophase Newtonian nanofluid flow hybrid with Hafnium particles under the effects of slip", Inventions, 5(1), p. 6 (2020).

18. Gul, M., Abbasi, F.M., Shehzad, S.A., and Shafee, A. "Entropy generation for peristaltic motion of Carreau's fluid with mixture of ethylene glycol and boron-nitride nanoparticles", Physica Scripta, 95(3), p. 035212 (2020).

19. Sarafraz, M.M., Pourmehran, O., Yang, B., Arjomandi, M., and Ellahi, R. "Pool boiling heat transfer characteristics of iron oxide nano-suspension under constant magnetic field", International Journal of Thermal Sciences, 147, p. 106131 (2020).

20. Crane, L.J. "Flow past a stretching plate", Zeitschrift für angewandte Mathematik und Physik ZAMP, 21(4), pp. 645-647 (1970).

21. Wang, C.Y. "The three-dimensional flow due to a stretching flat surface", The Physics of Fluids, 27(8), pp. 1915-1917 (1984).

22. Rajagopal, K.R., Na, T.Y., and Gupta, A.S. "Flow of a viscoelastic fluid over a stretching sheet", Rheologica Acta, 23(2), pp. 213-215 (1984). 
23. McLeod, J.B. and Rajagopal, K.R. "On the uniqueness of flow of a Navier-Stokes fluid due to a stretching boundary", In Analysis and Continuum Mechanics, Springer, Berlin, Heidelberg, pp. 565-573 (1989).

24. Abel, M.S., Siddheshwar, P.G., and Nandeppanavar, M.M. "Heat transfer in a viscoelastic boundary layer flow over a stretching sheet with viscous dissipation and non-uniform heat source", International Journal of Heat and Mass Transfer, 50(5-6), pp. 960-966 (2007).

25. Bataller, R.C. "Viscoelastic fluid flow and heat transfer over a stretching sheet under the effects of a nonuniform heat source, viscous dissipation and thermal radiation", International Journal of Heat and Mass Transfer, 50(15-16), pp. 3152-3162 (2007).

26. Yacob, N.A., Ishak, A., Pop, I., and Vajravelu, K. "Boundary layer flow past a stretching/shrinking surface beneath an external uniform shear flow with a convective surface boundary condition in a nanofluid", Nanoscale Research Letters, 6(1), p. 314 (2011).

27. Bachok, N., Ishak, A., and Pop, I. "Flow and heat transfer characteristics on a moving plate in a nanofluid", International Journal of Heat and Mass Transfer, 55(4), pp. 642-648 (2012).

28. Sharma, R., Ishak, A., and Pop, I. "Partial slip flow and heat transfer over a stretching sheet in a nanofluid", Mathematical Problems in Engineering, 2013, pp. 1-7 (2013).

29. Bachok, N., Ishak, A., Nazar, R., and Senu, N. "Stagnation-point flow over a permeable stretching/shrinking sheet in a copper-water nanofluid", Boundary Value Problems, 2013(1), p. 39 (2013).

30. Nazar, R., Amin, N., and Pop, I. "Unsteady boundary layer flow due to a stretching surface in a rotating fluid", Mechanics Research Communications, 31(1), pp. 121-128 (2004).

31. Sheikholeslami, M., Ashorynejad, H.R., Ganji, D.D. and Kolahdooz, A. "Investigation of rotating MHD viscous flow and heat transfer between stretching and porous surfaces using analytical method", Mathematical Problems in Engineering, Article ID 258734 (2011).

32. Aladag, B., Halelfadl, S., Doner, N., Maré, T., Duret, S., and Estellé, P. "Experimental investigations of the viscosity of nanofluids at low temperatures", Applied Energy, 97, pp. 876-880 (2012).

33. Halelfadl, S., Estellé, P., Aladag, B., Doner, N., and Maré, T. "Viscosity of carbon nanotubes water-based nanofluids: Influence of concentration and temperature", International Journal of Thermal Sciences, $\mathbf{7 1}$, pp. 111-117 (2013).

34. Khan, A.A., Usman, H., Vafai, K., and Ellahi, R. "Study of peristaltic flow of magnetohydrodynamics Walter's B fluid with slip and heat transfer", Scientia Iranica, 23(6), pp. 2650-2662 (2016).

35. Abbasi, F.M., Shanakhat, I., and Shehzad, S.A. "Entropy generation analysis for peristalsis of nanofluid with temperature dependent viscosity and Hall effects", Journal of Magnetism and Magnetic Materials, 474, pp. 434-441 (2019).

36. Sahoo, B. and Shevchuk, I.V. "Heat transfer due to revolving flow of Reiner-Rivlin fluid over a stretchable surface", Thermal Science and Engineering Progress, 10, pp. 327-336 (2019).

37. Shehzad, S.A., Reddy, M.G., Rauf, A., and Abbas, Z. "Bioconvection of Maxwell nanofluid under the influence of double diffusive Cattaneo-Christov theories over isolated rotating disk", Physica Scripta, 95(4), p. 045207 (2020).

38. Debnath, L. "On unsteady MHD boundary layers in a rotating flow", Recent Research in Unsteady Boundary Layers, Les Presses De L'Universite Laval, Quebec (1972).

39. Takhar, H.S. and Nath, G. "Unsteady flow over a stretching surface with a magnetic field in a rotating fluid", Zeitschrift für angewandte Mathematik und Physik, 49(6), pp. 989-1001 (1998).

40. Rosensweig, R.E. "Heating magnetic fluid with alternating magnetic field", Journal of Magnetism and Magnetic Materials, 252, pp. 370-374 (2002).

41. Kumari, M. and Nath, G. "Transient rotating flow over a moving surface with a magnetic field", International Journal of Heat and Mass Transfer, 48(14), pp. 28782885 (2005).

42. Kumari, M. and Nath, G. "Analytical solution of unsteady three-dimensional MHD boundary layer flow and heat transfer due to impulsively stretched plane surface", Communications in Nonlinear Science and Numerical Simulation, 14(8), pp. 3339-3350 (2009).

43. Kumaran, V., Banerjee, A.K., Kumar, A.V., and Pop, I. "Unsteady MHD flow and heat transfer with viscous dissipation past a stretching sheet", International Communications in Heat and Mass Transfer, 38(3), pp. 335-339 (2011).

44. Khan, Z.H., Khan, W.A., Qasim, M., and Shah, I.A. "MHD stagnation point ferrofluid flow and heat transfer toward a stretching sheet", IEEE Transactions on Nanotechnology, 13(1), pp. 35-40 (2013).

45. Sheikholeslami, M., Hatami, M., and Ganji, D.D. "Nanofluid flow and heat transfer in a rotating system in the presence of a magnetic field", Journal of Molecular Liquids, 190, pp. 112-120 (2014).

46. Khan, A.A., Usman, H., Vafai, K., and Ellahi, R. "Study of peristaltic flow of magnetohydrodynamics Walter's B fluid with slip and heat transfer", Scientia Iranica, 23(6), pp. 2650-2662 (2016).

47. Abbasi, F.M., Shanakhat, I., and Shehzad, S.A. "Analysis of entropy generation in peristaltic nanofluid flow with Ohmic heating and Hall current", Physica Scripta, 94(2), p. 025001 (2019).

48. Ellahi, R., Sait, S.M., Shehzad, N., and Mobin, N. "Numerical simulation and mathematical modeling of electro-osmotic Couette-Poiseuille flow of MHD powerlaw nanofluid with entropy generation", Symmetry, 11(8), p. 1038 (2019). 
49. Waqas, M., Jabeen, S., Hayat, T., Shehzad, S.A., and Alsaedi, A. "Numerical simulation for nonlinear radiated Eyring-Powell nanofluid considering magnetic dipole and activation energy", International Communications in Heat and Mass Transfer, 112, p. 104401 (2020).

50. Khan, L.A., Raza, M., Mir, N.A., and Ellahi, R. "Effects of different shapes of nanoparticles on peristaltic flow of MHD nanofluids filled in an asymmetric channel", Journal of Thermal Analysis and Calorimetry, 140, pp. 879-890 (2019).

51. Abbas, N., Nadeem, S., and Malik, M.Y. "On extended version of Yamada-Ota and Xue models in micropolar fluid flow under the region of stagnation point", Physica A: Statistical Mechanics and Its Applications, 542, p. 123512 (2020).

52. Ascher, U.M., Mattheij, R.M., and Russell, R.D. "Numerical solution of boundary value problems for ordinary differential equations", 13, Siam (1994).

53. Ascher, U.M. and Petzold, L.R. "Computer methods for ordinary differential equations and differentialalgebraic equations", 61, Siam (1998).

54. Noghrehabadi, A., Ghalambaz, M., and Samimi, A. "Approximate solution of laminar thermal boundary layer over a thin plate heated from below by convection", 2(2), pp. 45-57 (2013).

55. Wang, C.Y. "Stretching a surface in a rotating fluid", Zeitschrift für angewandte Mathematik und Physik ZAMP, 39(2), pp. 177-185 (1988).

56. Nadeem, S., Rehman, A.U., and Mehmood, R. "Boundary layer flow of rotating two phase nanofluid over a stretching surface", Heat Transfer-Asian Research, 45(3), pp. 285-298 (2016).

\section{Biographies}

Aziz Ur Rehman was born on June 14, 1968 in Chakwal, Punjab, Pakistan. He joined the Punjab Education Department (School Wing) on November
18, 1990 as an Elementary School Teacher and became a Secondary School Teacher in 2003. He obtained an M.Phil degree in 2010 and PhD degree in 2017 from the Department of Mathematics at Quaid-i-Azam University, Islamabad, Pakistan. He is Currently working as a lecturer in the Mathematics Department at Government College, Peer Phullahi District, Chakwal, under the Punjab Higher Education Department, Pakistan.

Sohail Nadeem is working as Professor/Chairman at the Department of Mathematics at Quaid-i-Azam University, Islamabad, Pakistan. More than $25 \mathrm{PhD}$ scholars and more than $100 \mathrm{M}$. Phil students have completed their respective degrees under his supervision. He has published more than 500 research articles in well reputed international journals, having more than 7000 citations. He has been awarded several national/international awards. He is also a member of several editorial boards in well reputed international journals. Nationally, he is serving on with several scientific committees throughout the country.

Nadeem Abbas was born on September 15, 1990 in District Jhang, Punjab, Pakistan. He earned his MS degree in Mathematics in 2014 from the University of the Punjab Lahore, Pakistan and a MPhil degree in 2017 from Quaid-i-Azam University Islamabad, Pakistan, where he is currently a PhD Scholar in the Department of Mathematics.

Rashid Mehmood was born in Rawalpindi, Punjab, Pakistan. He obtained his MPhil and PhD degrees from the Department of Mathematics at Quaid-iAzam University, Islamabad, Pakistan, and is currently working as Assistant Professor in the Department of Mathematics at HITEC University, Taxila Cantt, Rawalpindi, Punjab, Pakistan. More than $3 \mathrm{PhD}$ scholars and several M.Phil students have completed their respective degrees under his supervision. 